\section{Davy's Experiments on the Frictional Development of Heat}

In Nature for March 9, 1935 (p. 359), Prof. Andrade directed attention to the persistent textbook errors concerning Davy's experiments on the frictional development of heat, pointing out, among other things, that the much-quoted experiment on the melting of two pieces of ice by rubbing them together was not carried out in a vacuum. It may be of some interest to inquire how Davy produced and maintained the vacuum for the first experiment, in which a gunlock was fired, and for the third experiment, in which wax was melted by the heat developed by the friction of a wheel rotated by clockwork against the plate carrying the wax. Davy gives no details of his vacuum apparatus, but refers to the "exhausted receiver" of an "air-pump". In the first experiment the trigger of the gunlock was snapped, he says, by this means: "A slight iron wire was affixed to the trigger, brought through a hole made in the centre of the stand [supporting the receiver], and cemented into the hole with wax, so as to exclude entirely atmospheric air from the receiver"1. Presumably the same device was used in the third experiment to start the clockwork.

In neither case would a vacuum be maintained. As for the apparatus by which the vacuum was produced, it appears to have been an 'air-pump' with a curious history, indeed, a curiosity itself. Davy had shown some kindness to the surgeon of a French ship wrecked at the Land's End, and in return the latter gave him certain instruments, including a glyster or enema syringe, which Davy converted in some way or other into an air-pump. This account is given by Paris ${ }^{2}$, who states that he obtained it from Thomas Giddy of Penzance. John Davy, however, in writing his brother's biography, discredited Paris's story of the syringe, alleging that "Mr. Giddy probably had it from some facetious person who wished to amuse him ... because no one belonging to our family ever heard of this instrument, or of the French surgeon, or of the shipwrecked French vessel off the Land's End, so circumstantially noticed in Dr. Paris's lively narrative"3. While Paris's account is reasonably credible in view of the scant facilities likoly to be available to a youth of nineteen in such a remote part of the country as Penzance, John Davy's denial is not improbably due to his extensive irritation with Paris's Stracheyan sense of a biographer's duties.

History of Science Department,

Douglas MCKIE.

University College, W.C.1.

1 "Contributions to Physical and Medical Knowledge", etc., ed. Thomas Beddoes, Bristol, 1799, p. 9 .

" "Life of Sir Humphry Davy", London, 1831, I, pp. 41-2.

${ }^{3}$ "Memoirs of the Life of Sir 'Humphry Davy", London, 1836, I, pp. $43-4$.

\section{Identity of Calycopterin and Thapsin}

A sELLOW colouring matter with powerful anthelminthic properties has recently been isolated ${ }^{1}$ from the leaves of Calycopteris floribunda, Lamk., and the constitution of a dihydroxytetramethoxyflavone ascribed to it. Since it yielded $p$-hydroxybenzoic acid by degradation with alkali, it became obvious that all the six positions of the fused benzene ring were occupied and the substance was a remarkable instance of a pentahydroxybenzene derivative occur- ring in Nature. Demethylation gave a new hexahydroxyflavone, 'calycopteretin'.

While this work was going on, one of $\mathrm{us}^{2}$ obtained a by-product, thapsin, in the preparation of digitoxin from a dried and powdered specimen of the leaves of a Spanish Digitalis, the botanical source of which was uncertain, but was very probably derived from Digitalis thapsi, L. The independently described properties of calycopterin and thapsin are very similar and direct comparison of the two substances and their dimethyl ethers has shown their complete identity. The occurrence of a flavone with so unusual an orientation of hydroxyl and methoxyl groups in two plants belonging to widely different natural orders (one to the Combretaceæ and the other to the Scrophulariaceæ) is worth notice.

With regard to the slight precedence in point of time, we suggest that the name calycopterin may be retained for the flavone constituents of both Calycopteris floribunda and Digitalis thapsi.

\section{W. KARRER.}

K. Venkataraman.

Laboratory of F. Hoffmann-La Roche and Co., Basle.

Department of Chemical Technology, University, Bombay.

1 Ratnagiriswaran, Sehra and Venkataraman, Biochem. J., 28, 1964 1934.

${ }^{2}$ Karrer, Helv. Chim. Acta, 17, 1560 ; 1934.

\section{Philosophical Interpretation of Science}

WHILE it is true that Prof. Dingle ${ }^{1}$ and I can finish this discussion in private, it seems to me there is a public importance in differentiating the two schools of thought. One school claims that science is an historical phenomenon produced by human beings in their handling of the world of which they are parts, a social practice with technological, experimental and theoretical aspects all interlocking and interdependent. Scientists it sees as individuals consciously or unconsciously fulfilling the social purpose of science even when they are personally interested only in developing its logical framework. I agree with that view of science.

There is the other school that sees science simply as the organisation of our experiences in logical form. Prof. Dingle even goes further than this for he asserts that "the logical network is the external world", and he believes this to be a consequence of scientific discovery. It was this to which I took exception, and I doubt whether either Einstein or Bohr, whom he has quoted in support, would underwrite this. Be that as it may, the first view sees science in its social context, sees it socially conditioned, and keeps the scientist alive to the social consequences of his work. The second view banishes the world into a set of logical ideas. The first view says that science and philosophies are produced by man, are manifestations of his social behaviour and therefore exist with him in the external world. The second view leads Prof. Dingle to say "It certainly never occurred to me to claim that the external world contained philosophies". The two schools evidently speak different languages.

Imperial College of Science,

H. Levy.

\section{S.W.7.}

${ }^{1}$ Nature, 135, 793, May 11, 1935. 